\title{
Erasmus Mundus Master of Bioethics
}

\section{Partners}

Catholic University of Leuven, Belgium (Co-ordinating Institution) Radboud University Nijmegen, The Netherlands, University of Padova, Italy

\section{Course description}

This particular Master's programme was first organised in 1998 by the Radboud University Nijmegen (the Netherlands), the Catholic University of Leuven (Belgium) and the University of Padova (Italy).

The main objective of the Master of Bioethics is to train highly qualified students for research work or professional activities in the interdisciplinary field of bioethics, a field that is increasingly confronted with different moral questions and dilemmas. It approaches bioethics from an international perspective, paying special attention to European philosophical and theological traditions in this area. It has a wider theoretical perspective than the analytical, applied ethics approach dominant in the Anglo-Saxon tradition. Themes such as personalism, communitarianism, hermeneutic ethics, social ethics, and empirical work in ethics will be strongly emphasised. Philosophical and theological theories about the concept of the person, the human body, solidarity, the meaning of life and death, care, goals of medicine, and the technological imperative will also underpin study. Complementing these theoretical perspectives, the programme has a strong interdisciplinary character, directing its ethical reflection toward specific areas. Attention is also focused on the clinical and practical health care settings in which ethical issues arise.

The Master of Bioethics takes 1 year, during which students study for an equal period of time at the three participating universities. Each university offers courses on the basis of its own approach and expertise, in such a way that students can benefit from different cultural and scholarly traditions. The language of instruction is English, and the programme has an excellent professor/student ratio (4 professors to every 3 students).

Successful students will receive a joint degree diploma signed by the rectors of the three participating universities.

\section{Admission}

Only holders of a Master's degree will be accepted to the programme. Applicants should have a proven competency in English, and have had education, experience or involvement in the field of health care or bioethics. Academic results, training, professional activities and publications will all be taken into consideration in the assessment of the applicants.

\section{Scholarships}

More than 20 students and 3 scholars will be enabled to participate in the Master of Bioethics with financial aid of Erasmus Mundus scholarships. Nationals coming from all countries other than the $25 \mathrm{EU}$ Member States, the EEA-EFTA states and the candidate countries for accession to the EU, and who have not carried out their main activities (studies, work, etc.) for more than a total of 12 months over the last 5 years in any of the above countries can be selected for the Erasmus Mundus scholarships.

\section{Contact:}

\author{
A. Leysen \\ Centre for Biomedical Ethics and Law \\ Kapucijnenvoer 35/3, 3000, \\ Leuven, Belgium \\ e-mail: masterbioethics@med.kuleuven.be
}

